http://jmscr.igmpublication.org/home/

ISSN (e)-2347-176x ISSN (p) 2455-0450

crossref DOI: https://dx.doi.org/10.18535/jmscr/v9i11.19

Journal Of Medical Science And Clinical Research

IGM Publication

An Official Publication of IGM Publication

\title{
Correlation of Gallbladder Volume to Autonomic Neuropathy in Diabetics
}

Authors

\section{Dr Patimalla Visala Bhavishya, Dr M .Madhusudhana Babu, MD, DM., Dr K. Sudheer, MD}

GEMS Hospital, Srikakulam, Andhra Pradesh, India

\section{Introduction}

- Diabetes mellitus is most common endocrine disorder in humans characterized by chronic hyperglycemia due to defects in insulin secretion, insulin action or both

- Prevalence of diabetes in adults in India is around $8.9 \%$

- Complications of diabetes can be divided into acute \& chronic complications

- Acute complications include diabetic ketoacidosis, non ketotic hyperosmolar state, hypoglycemia.

- Chronic complications can be divided into microvascular \& macrovascular complication

- Microvascular complications include eye disease (retinopathy, macularedema, cataracts), neuropathy (sensory \& motor, autonomic), nephropathy

- Macrovascular complications include coronary artery disease, peripheral artery disease, cerebrovascular disease

- Diabetes is the commonest cause of autonomic peripheral neuropathy. A broad spectrum of symptoms affecting cardiovascular, gastrointestinal, urogenital, thermoregulatory, sudomotor \& pupillomotor function canoccur

- Gall bladder involvement in diabetic autonomic neuropathy occurs in form of increased gall bladder volume \& impaired gall bladder contraction

- Vagal parasympathetic fibers maintain gall bladder tone \& influence it's emptying

- Hence gall bladder dysfunction may occur in autonomic neuropathy

- Due to impaired contraction, stasis occurs and results in gall stone formation

- Therefore gall bladder function should be routinely evaluated in diabetic patients

Aim

To assess the gall bladder volume in patients with type 2 diabetes mellitus and it's comparison in relation to autonomic neuropathy

\section{Materials and Methods}

Source of Study: The material of this study comprised of forty patients of type 2 diabetes mellitus admitted in GEMS hospital, Srikakulam, Andhra Pradesh.

Study Designs: Cross sectional study

Study Period: November 2019 - August2020

Duration of Study: 10 months 


\section{JMSCR Vol||09||Issue||11||Page 100-106||November}

\section{Inclusion Criteria}

1. Duration of diabetes $>5$ years

2. Well compliant to anti diabetic medication

\section{Exclusion Criteria}

1. Cardiac arrhythmias

2. Patients on anti HTN medication which interferes with autonomic function

3. Obese patients, pregnantladies

4. Past history of CVA

5. Patients with HIV infections

\section{Collection of Data}

This is a cross sectional study

- Patients were investigated with RBS, FBS, PPBS, HbA1c for good glycemic control

- FBS (90-130mg \%), PPBS (<180mg\%),
$\operatorname{HbA1c}(<7 \%)$ was taken for deciding glycemic control

- Ultrasonography abdomen was done to assess the gall bladder volume

- Cardiac autonomic neuropathy was tested by BP response to standing, HR variation from supine to standing, HR variation to deep breathing \& BP response to sustained handgrip

- Other investigations like haemoglobin, TLC, DLC, ESR, urine routine, ECG, blood urea, serum creatinine were done

- Statistical analysis was done using student $\mathrm{t}$ test and $\mathrm{p}$ value $<0.05$ was considered significant

\section{Age Distribution}

\begin{tabular}{|c|c|c|}
\hline Age in years & No of patients & Percentage \\
\hline $41-50$ & 22 & 55 \\
\hline $51-60$ & 10 & 25 \\
\hline $61-70$ & 7 & 17.5 \\
\hline $71-80$ & 1 & 2.5 \\
\hline Total & 40 & 100 \\
\hline
\end{tabular}

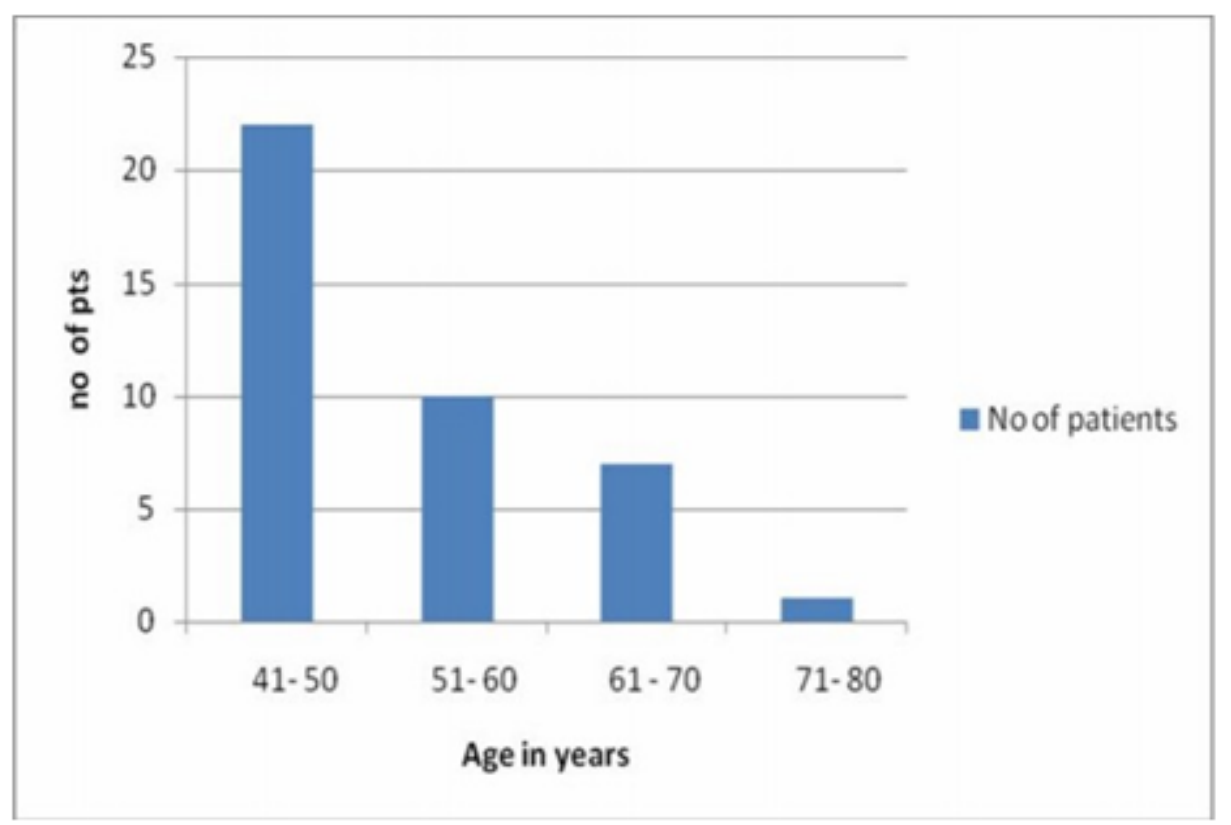


Diabetics With \& Without Autonomic Neuropathy

\begin{tabular}{|l|l|l|}
\hline & No of pts & Percentage \\
\hline DM with autonomic & 13 & 22.5 \\
\hline DMeuropathy without autonomic & 27 & 67.5 \\
\hline Total & & \\
\hline
\end{tabular}

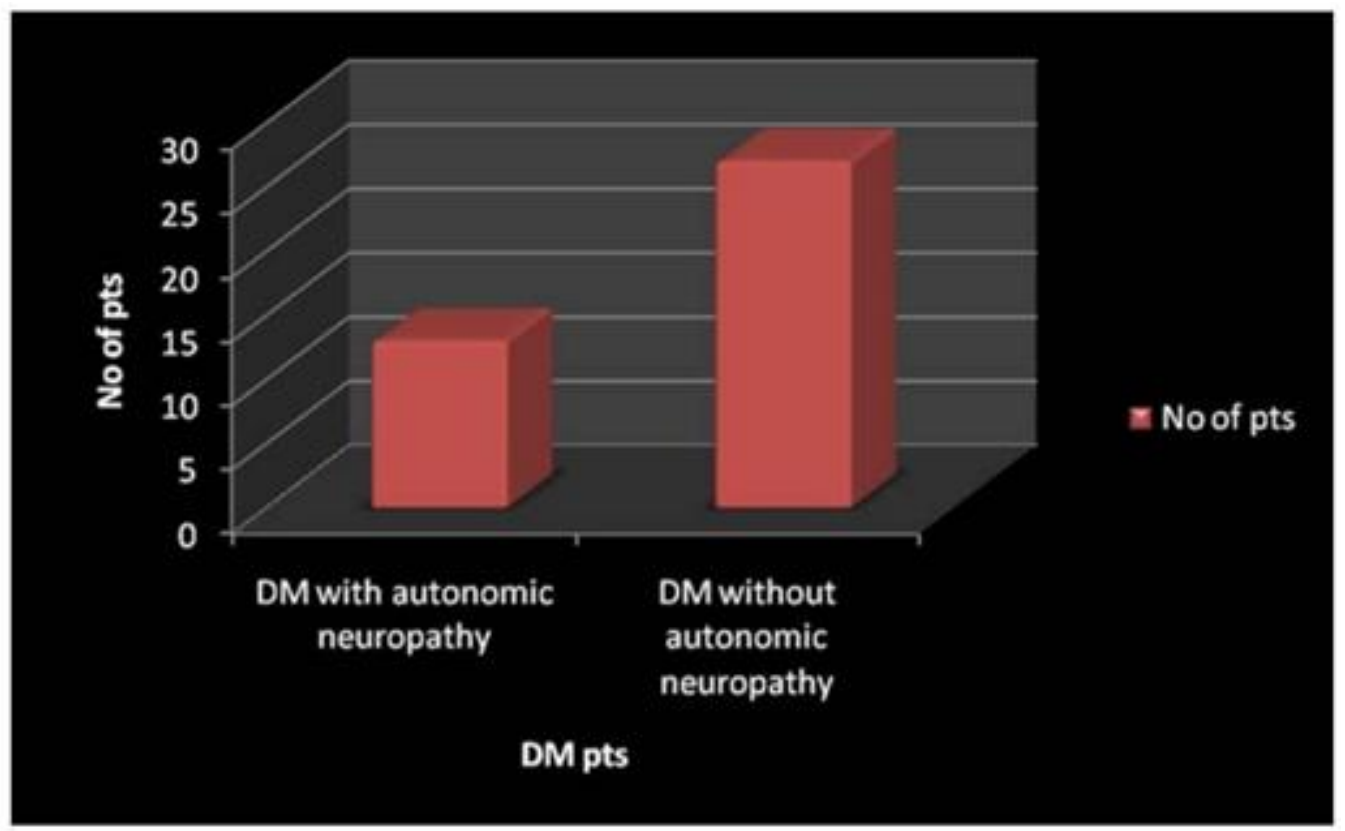

Duration of Diabetes Mellitus

\begin{tabular}{|c|c|c|}
\hline $\begin{array}{c}\text { Duration of DM } \\
\text { (yrs) }\end{array}$ & $\begin{array}{c}\text { DM with } \\
\text { autonomic } \\
\text { neuropathy }\end{array}$ & $\begin{array}{c}\text { DM without } \\
\text { autonomic } \\
\text { neuropathy }\end{array}$ \\
\hline $5-7$ yrs & 5 & 22 \\
\hline $8-10 y r s$ & 4 & 0 \\
\hline $11-13 y r s$ & 2 & 0 \\
\hline $14-16 y r s$ & 2 & 27 \\
\hline Total & 13 & \\
\hline
\end{tabular}




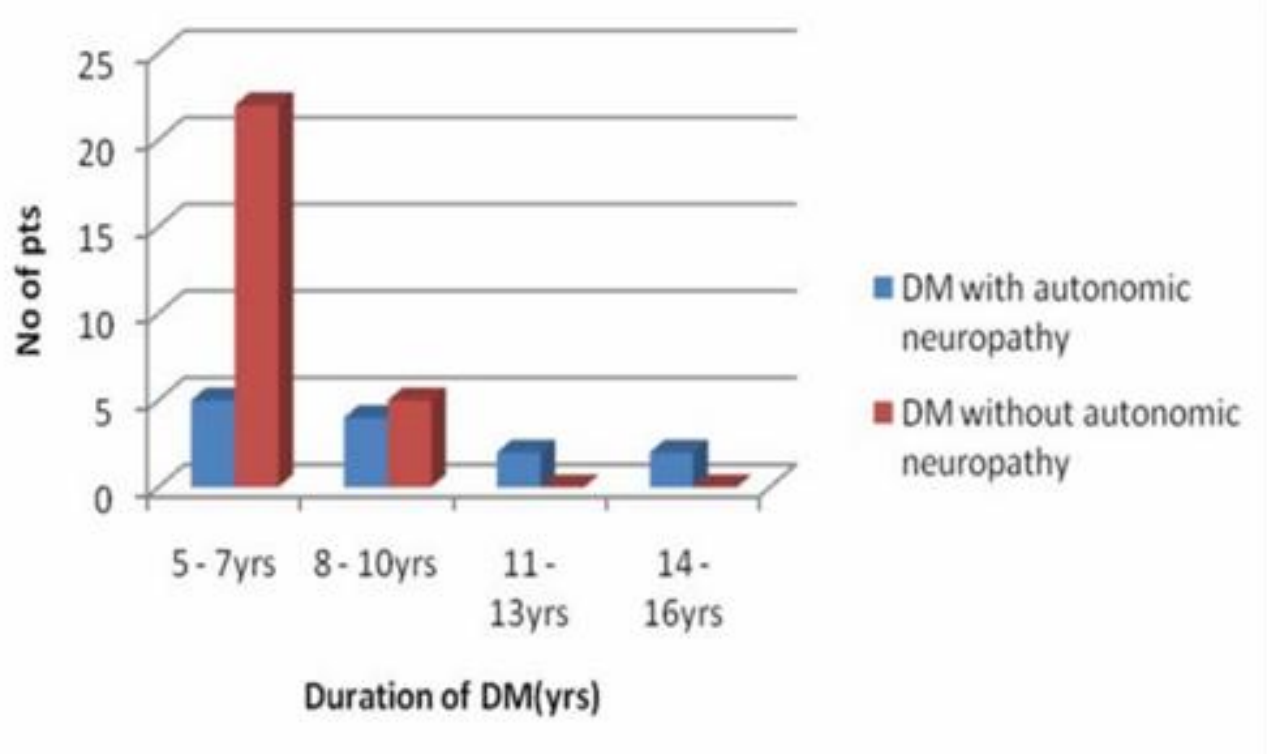

\begin{tabular}{|l|c|c|}
\hline FBS(mg\%) & $\begin{array}{c}\text { DM with autonomic } \\
\text { neuropathy }\end{array}$ & $\begin{array}{c}\text { DM without autonomic } \\
\text { neuropathy }\end{array}$ \\
\hline $71-80$ & 1 & 1 \\
\hline $81-90$ & 1 & 3 \\
\hline $91-100$ & 1 & 9 \\
\hline $101-110$ & 4 & 11 \\
\hline $111-120$ & 5 & 4 \\
\hline $121-130$ & 1 & 0 \\
\hline Total & 13 & 27 \\
\hline
\end{tabular}

\begin{tabular}{|l|c|c|}
\hline$+\bullet+\bullet B S(m g \%)$ & $\begin{array}{c}\text { DM with autonomic } \\
\text { neuropathy }\end{array}$ & $\begin{array}{c}\text { DM without autonomic } \\
\text { neuropathy }\end{array}$ \\
\hline $131-140$ & 0 & 0 \\
\hline $141-150$ & 0 & 1 \\
\hline $151-160$ & 1 & 2 \\
\hline $161-170$ & 6 & 8 \\
\hline $171-180$ & 6 & 16 \\
\hline Total & 13 & 27 \\
\hline
\end{tabular}

\begin{tabular}{|l|c|c|}
\hline HbAlc & $\begin{array}{c}\text { DM with autonomic } \\
\text { neuropathy }\end{array}$ & $\begin{array}{c}\text { DM without } \\
\text { Autonomic neuropathy }\end{array}$ \\
\hline $6.1-6.2$ & 1 & 1 \\
\hline $6.3-6.4$ & 1 & 4 \\
\hline $6.5-6.6$ & 4 & 6 \\
\hline $6.7-6.8$ & 4 & 7 \\
\hline $6.9-7$ & 3 & 9 \\
\hline Total & 13 & 27 \\
\hline
\end{tabular}




\section{JMSCR Vol||09||Issue||11||Page 100-106||November}

\section{Gall Bladder Volume}

\begin{tabular}{|l|l|l|}
\hline GB volume & DM with autonomic & DM without autonomic \\
& neuropathy & neuropathy \\
\hline $0-20$ & 0 & 20 \\
\hline $21-40$ & 3 & 7 \\
\hline $41-60$ & 7 & 0 \\
\hline $61-80$ & 3 & 0 \\
\hline Total & 13 & 27 \\
\hline
\end{tabular}

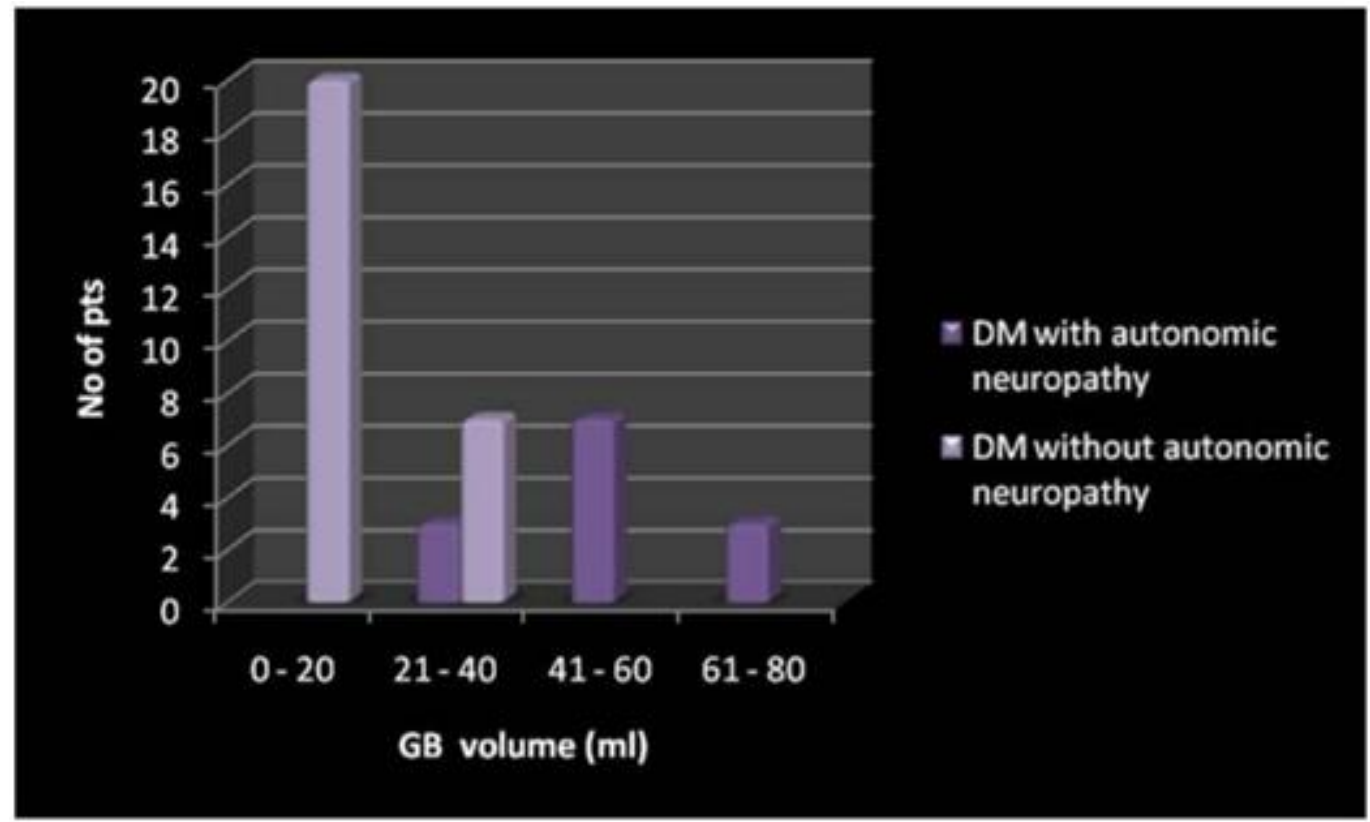

Gall Bladder Volume with Age of the Patients

\begin{tabular}{|l|c|c|c|c|c|}
\hline & \multicolumn{5}{|c|}{ Age (yrs) } \\
\hline GB & $31-40$ & $41-50$ & $51-60$ & $61-70$ & $71-80$ \\
\hline $0-20 \mathrm{ml}$ & 0 & 15 & 3 & 1 & 1 \\
\hline $21-40 \mathrm{ml}$ & 0 & 5 & 3 & 2 & 0 \\
\hline $41-60 \mathrm{ml}$ & 0 & 1 & 3 & 3 & 0 \\
\hline $61-80 \mathrm{ml}$ & 0 & 1 & 1 & 1 & 0 \\
\hline Total & $\mathbf{0}$ & $\mathbf{2 2}$ & $\mathbf{1 0}$ & $\mathbf{7}$ & 1 \\
\hline
\end{tabular}




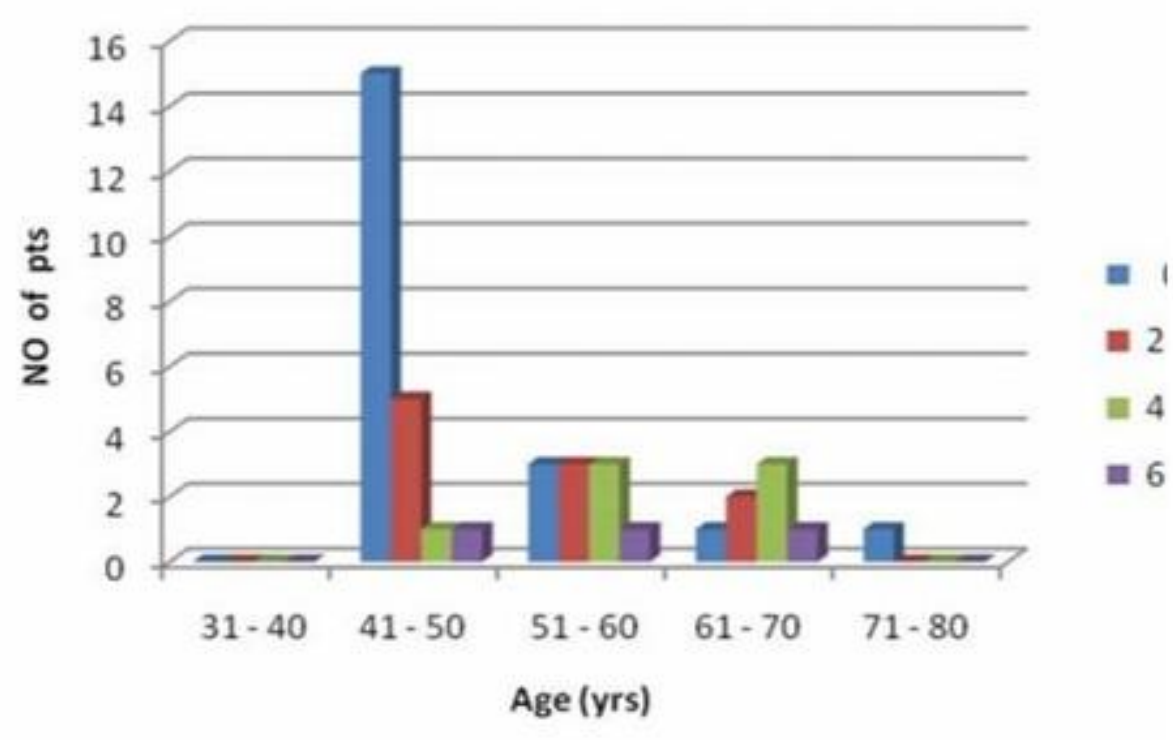

Gall Bladder Volume with Duration of Diabetes

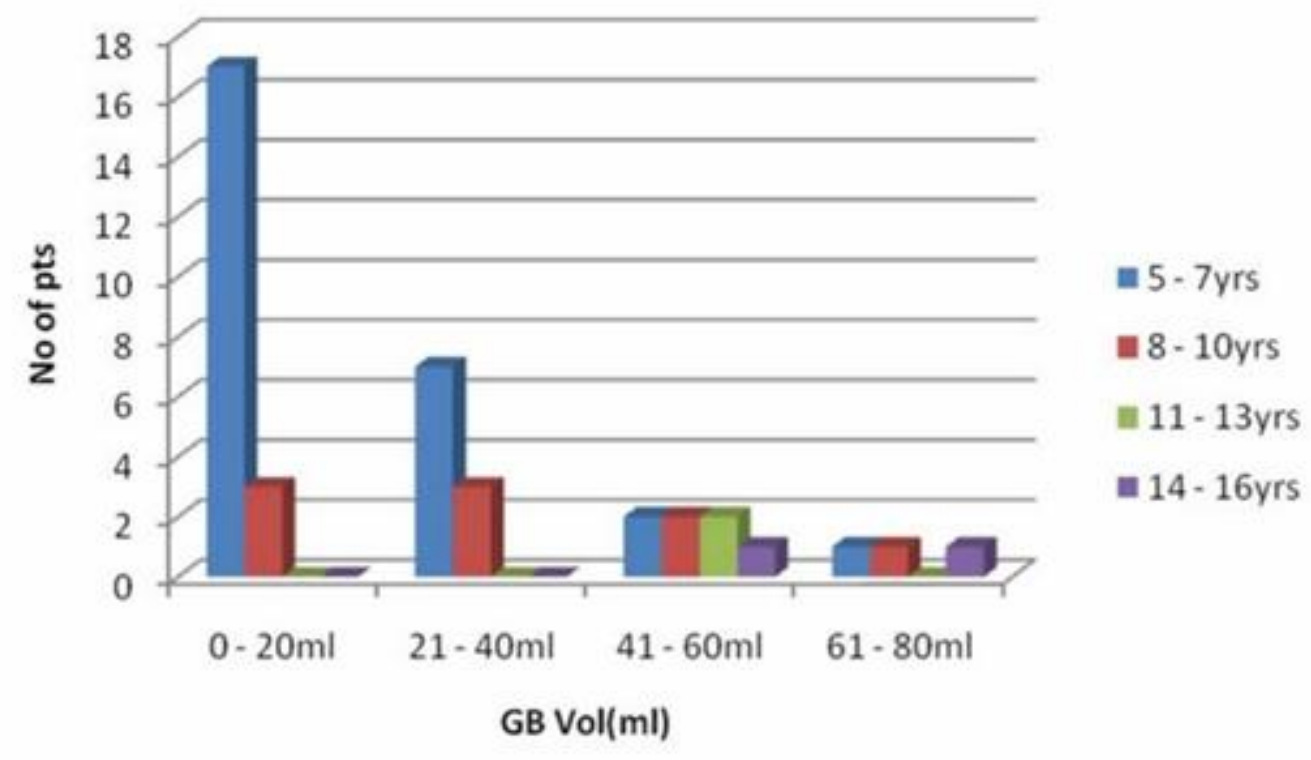

\section{Summary}

- Diabetic neuropathy in one of the major complications of long standing diabetes

- Neural control of gall bladder emptying is mediated by both sympathetic\& parasympathetic, the former increases the gallbladder contractility \&later causes relaxation

- This is a cross sectional study of 40 diabetic patients

- Gall bladder volume was evaluated by ultrasonography \& compared with\& without autonomic neuropathy

- Cardiac autonomic neuropathy was tested in all 40 patients with simple bed side tests

- Patients age ranged from 41-76yrs. Majority of patients were in 41-50 yrs age group. Mean age was $52.60+/-8.145 \mathrm{yrs}$

- The duration of diabetes ranged from 5$15 \mathrm{yrs}$ with a mean duration of $7.28+/-$ 2.50yrs. Patients with cardiac autonomic neuropathy had longer duration of diabetes than without cardiac autonomic neuropathy

- Patients with cardiac autonomic 
neuropathy had larger gall bladder volume $(52.54+/-14.234 \mathrm{ml})$ than patients without cardiac autonomic neuropathy (18.19+/$4.35 \mathrm{ml})$

\section{Conclusion}

- The gall bladder volume was higher in diabetics with autonomic neuropathy when compared with diabetics without autonomic neuropathy

- Gall bladder volume was more with higher age group patients

- $\quad$ The age \&duration of diabetics were higher in diabetics with autonomic neuropathy

- A significant association of autonomic neuropathy with increase in gall bladder volume has been demonstrated

\section{References}

1. A K Agarwal, S Miglani, S Singla, U Garg, R K Dudeja, A Goel Ultrasonographic evaluation of gall bladder volume in diabetics. JAPI,vol 52,962-965,2004.

2. S Singh, R Chander, A Singh, S Mann . Ultrasonographic Evaluation ofGall Bladder Diseases In diabetes Mellitus Type 2 .Ind J Radiol Imag 200616:4:505508.

3. Alvin C Powers -Diabetes mellitus p2275 2310 Anthony S. Fauci, Eugene Braunwald, Dennis L. Kasper, Stephen L. Hauser, Dan L. Longo, 1. Larry Jameson et al in Harrison $\mathrm{s}$ principles of internal medicine 17thed.

4. Ewing D.J et al, 1986 "Autonomic neuropathy its diagnosis and prognosis". Clinics in Endocrinology and Metabolism, 15 (4) : 855885pp.

5. Murray A et al, 1975 "RR Interval variation in young male diabetes".BMJ,37: 882-885 pp.
6. Timothy J.B et al, 1990 "Heart rate variability and cardiacautonomic function In diabetes". Diabetes, 39: 1177-81pp.

7. Albert B. Levin, 1966 "A simple test of cardiac function based upon heartrate charges induced by the valsalva manoeuve". The Am J of Cardiology, Vol. 18: 90-99pp.

8. Raman P G, Patel A, Mathew V, Gall bladder disorders and type 2 diabetes mellitus-A clinical based study. JAPI 2002, 50;887-889.

9. Guliter, Sefa M D, Ylmaz, Serda M D, Korakan, Taekan M D. Evaluation of gall bladder volume and motility in NIDDM patients using real-time ultrasonography. Journal of clinical Gastroenterology 37(4): 288- 299, octosee, 2003. 